\title{
Determinants of In-Hospital Death Among the Very Elderly with Acute Myocardial Infarction
}

\author{
Masaru Seguchi, ${ }^{1}$ MD, Kenichi Sakakura, ${ }^{1}$ MD, Takunori Tsukui, ${ }^{1}$ MD, Kei Yamamoto, ${ }^{1}$ MD, \\ Yousuke Taniguchi, ${ }^{1}$ MD, Hiroshi Wada, ${ }^{1}$ MD, Shin-ichi Momomura, ${ }^{1}$ MD and Hideo Fujita, ${ }^{1}$ MD
}

\begin{abstract}
Summary
Since the number of elderly patients suffering from acute myocardial infarction (AMI) has been increasing in developed countries, primary percutaneous coronary intervention (PCI) for the very elderly aged $\geq 80$ years old is already common. The study aimed to examine the determinants of in-hospital death among the very elderly with AMI in current PCI era. We included 412 consecutive AMI patients aged $\geq 80$ years old who received PCI to the culprit lesion; however, 42 patients (10.2\%) died during the index hospitalization. Thus, univariate and multivariate logistic regression analyses were performed to identify the determinants of in-hospital death. Of note, the modified KATZ index, which is a seven-point scale ranging from 0 to 6 ( 0 point indicating no dependence and six points indicating full dependence), was calculated to evaluate pre-admission activity of daily living (ADL). In multivariate analysis, cardiac arrest (OR 4.642, 95\% CI 1.177-18.305, $P=0.028$ ), Killip class IV (versus Killip class I: OR 5.732, 95\% CI 1.076-16.630, $P=0.001)$, modified KATZ index (OR 1.212, 95\% CI 1.001-1.469, $P=0.049$ ), hemoglobin levels (OR 0.803, 95\% CI 0.656-0.983, $P=0.033$ ), use of temporary pacemaker (OR 2.603, 95\% CI 1.010-6.709, $P=0.048$ ), final Thrombolysis In Myocardial Infarction (TIMI) flow grade 3 (versus TIMI $\leq 2$ : OR $0.240,95 \%$ CI $0.093-0.618, P=0.003$ ), and mechanical circulatory support (OR 4.264, 95\% CI 1.818-10.005, $P=0.001$ ) were found to be significantly associated with in-hospital death. In conclusion, in-hospital outcomes of the very elderly with AMI were still poor in the current PCI era. Poor pre-admission ADL as well as cardiogenic shock and anemia were determined to be strongly associated with inhospital death.
\end{abstract}

(Int Heart J 2020; 61: 879-887)

Key words: Aging, Coronary intervention, Frailty, Ischemic heart disease

A s population aging is rapidly progressing, the number of people aged $\geq 80$ years old has exceeded 10 million in Japan. ${ }^{1}$ Furthermore, the proportion of people aged $\geq 80$ years old will be estimated to increase by $11.1 \%$ in 2025 and by $14.5 \%$ in 2035 in Japan. ${ }^{1)}$ As a matter of course, the number of elderly patients identified to have acute myocardial infarction (AMI) is also rapidly increasing in Japan and other developed countries. ${ }^{2,3)}$ Therefore, primary percutaneous coronary intervention (PCI) for patients aged $\geq 80$ years old with AMI is not considered an uncommon treatment approach. ${ }^{4)}$ This would be the first step to stratify high-risk patients for better outcomes in the very elderly with AMI. Because the very elderly with AMI often have multiple comorbidities ${ }^{5}$ and complex coronary artery lesions, ${ }^{6}$ the determinants of poor clinical outcomes may be different compared to those of younger patients. The aim of this study was to investigate the determinants of in-hospital death among the AMI patients aged $\geq 80$ years old in current PCI era.

\begin{abstract}
Methods
Study population: We reviewed consecutive AMI patients in our medical center from January 2009 to June 2019. We excluded the following patients: (1) the patients aged $<80$ years old, (2) the patients who did not receive PCI to the culprit lesion of AMI, and (3) the patients whose pre-admission ADL was not recorded. We then divided the study population into two groups: (1) survived group, consisting of patients who survived until the hospital discharge, and (2), in-hospital death group, consisting of patients who reportedly died during the index hospitalization. Clinical characteristics, procedures, and clinical outcomes were compared between the two groups. We sought to identify the determinants of in-hospital death using univariate and multivariate logistic regression analysis. This study was approved by the institutional review board, and written informed consent was waived because of its retrospective study design. This study was conducted in accordance with the principles of the Declaration of Helsinki.
\end{abstract}

Definition: The diagnosis of AMI required the following

From the ${ }^{1}$ Division of Cardiovascular Medicine, Saitama Medical Center, Jichi Medical University, Saitama, Japan.

Address for correspondence: Kenichi Sakakura, MD, Division of Cardiovascular Medicine, Saitama Medical Center, Jichi Medical University, 1-847 Amanuma, Omiya-ku, Saitama, Saitama, 330-8503, Japan. E-mail: ksakakura@jichi.ac.jp

Received for publication March 7, 2020. Revised and accepted June 3, 2020.

Released in advance online on J-STAGE September 12, 2020.

doi: $10.1536 /$ ihj.20-165

All rights reserved by the International Heart Journal Association. 
criteria: symptoms consistent with AMI, elevated cardiac enzymes including troponin $\mathrm{T}$, troponin $\mathrm{I}$, and/or creatinine kinase (at least twofold increase from the normal upper limit), and ST-segment elevation or depression in electrocardiograms compatible with AMI. ${ }^{7}$ Diagnostic ST elevation was defined as the new ST elevation at the J point in at least two contiguous leads of $2 \mathrm{~mm}(0.2 \mathrm{mV})$, and the AMI patients with ST elevation were then diagnosed with ST elevation myocardial infarction (STEMI). The other AMI patients without ST elevation were defined as non-ST elevation myocardial infarction. Hypertension was defined as medical treatment for hypertension or a history of hypertension before admission. ${ }^{9)}$ Dyslipidemia was defined as medical treatment for dyslipidemia or a history of dyslipidemia. Diabetes mellitus was defined as a hemoglobin A1c level (as NGSP value) $\geq 6.5 \%$, medical treatment for diabetes mellitus, or a history of diabetes mellitus. ${ }^{10)}$ Anemia was defined as a hemoglobin level < $13 \mathrm{~g} / \mathrm{L}$ in men and < $12 \mathrm{~g} / \mathrm{L}$ in women. ${ }^{11)}$ We used the laboratory data at admission. Since we could not measure some laboratory data such as HbA1c or low-density lipoprotein (LDL) cholesterol levels at off-hours (night or holidays), we substituted them using the earliest HbA1c or LDL cholesterol levels since admission. Significant coronary artery stenosis has been defined as at least a $75 \%$ reduction in the internal diameter. The reference diameter and lesion length were calculated using quantitative coronary angiographic analysis. Offline, computerbased software QAngio XA 7.3 (MEDIS Imaging Systems, Leiden, the Netherlands) was used for the quantitative coronary angiographic analysis. ${ }^{12}$ Initial and final Thrombolysis In Myocardial Infarction (TIMI) flow grade were recorded. ${ }^{13)}$ The diameter and length of the stent were recorded. If multiple stents were used for the culprit of AMI, an average diameter of all deployed stents was recorded as the stent diameter, and the sum of all the deployed stents' length was recorded as the stent length. Left ventricular ejection fraction (LVEF) was measured by transthoracic echocardiography during hospitalization. LVEF was calculated by either using modified Simpson's rule, Teichholz method, or eyeball estimation. Ejection fraction measured using a Teichholz method/eyeball estimation was adopted only when a modified Simpson method was not available. The use of mechanical circulatory support including intra-aortic balloon pumping support (IABP) and veno-arterial extracorporeal membrane oxygenation (VA-ECMO) was also recorded.

Primary PCI: Although we did not perform PCI to patients who were uncooperative with the cardiac catheterization procedure or those who failed to understand the necessity of PCI because of cognitive dysfunction, we performed PCI to the culprit of AMI regardless of the patient's age. In our catheter laboratory, primary PCI were performed using standard techniques via radial artery, femoral artery, or, rarely, brachial artery. First, we advanced a conventional guidewire across the lesion and then used a small balloon or thrombus aspiration catheter. The device of choice was left to the discretion of each interventional cardiologist. Activated coagulation time was maintained $>250$ seconds during PCI.

Pre-admission ADL: In our institution, we routinely in- terviewed the patients and/or their representatives about pre-admission ADL. A questionnaire regarding preadmission ADL was consisted of six variables: having meals, using toilets, maintaining cleanliness, washing face, changing clothes, and moving around. Those six variables were evaluated either independent or dependent at their admission. Our six variables were found similar to the variables which Katz, et al. reported. ${ }^{14)}$ Katz reported the index of ADL which consisted with six variables: feeding (having meal), continence (maintaining cleanliness), transferring (moving around), going to the toilet (using the toilet), dressing (changing clothing), and bathing. The Katz score was then modified to exclude bathing as this is considered not appropriate in a Japanese context. Dependence on facial washing was used as a surrogate instead. Because it would take more efforts to bathe in Japanese style than having a shower, most of frail elderly would not bathe independently with Japanese style. Hence, our six variables would reflect real ADL in Japan. To evaluate pre-admission ADL, the sum of six variables was calculated as "modified KATZ (mKATZ) index" in this study. The index is a 7-point scale ranging from 0 to 6 , with 0 point indicating no dependence and 6-point indicating dependence on all variables.

Statistical analysis: Data were expressed as mean \pm SD for continuous variables and percentage for categorical variables. Categorical variables were then compared using the Pearson's chi-squared test or the Fischer exact test. The Shapiro-Wilk test was performed to determine if the continuous variables were normally distributed. Normally distributed continuous variables were then compared using an unpaired Student's $t$-test. Otherwise, continuous variables were compared using a Mann-Whitney $U$-test. The multivariate stepwise logistic regression analysis was performed to in order to identify the determinants of inhospital death. This model included independent variables found to have an association with in-hospital death in univariate analysis (defined as $P<0.05$ ). ${ }^{15)}$ Furthermore, variables including missing values were not included in the multivariate model. The odds ratio (OR) and the $95 \%$ confidence interval (CI) were calculated. A p-value less than 0.05 was considered to be statistically significant. All analyses were performed using statistical software, SPSS 24.0/Windows (SPSS, Chicago, IL, USA).

\section{Results}

A total of 491 AMI patients aged $\geq 80$ years old were admitted to our hospital during the study period. Among them, 60 patients were excluded because they did not receive PCI to the culprit lesion of AMI. In-hospital mortality of those 60 patients was recorded to be at $21.7 \%$. We also excluded 19 patients whose pre-admission ADL was not recorded. In-hospital mortality of those 19 patients was at $31.6 \%$. In total, the remaining 412 patients were included as the final study population. In the final study population, 42 patients $(10.2 \%)$ died in the index admission. Therefore, the study patients were divided into the survived group $(n=370)$ and the in-hospital death group $(n=42)$ (Figure). Among the in-hospital death group, only one patient died of interstitial pneumonia, 


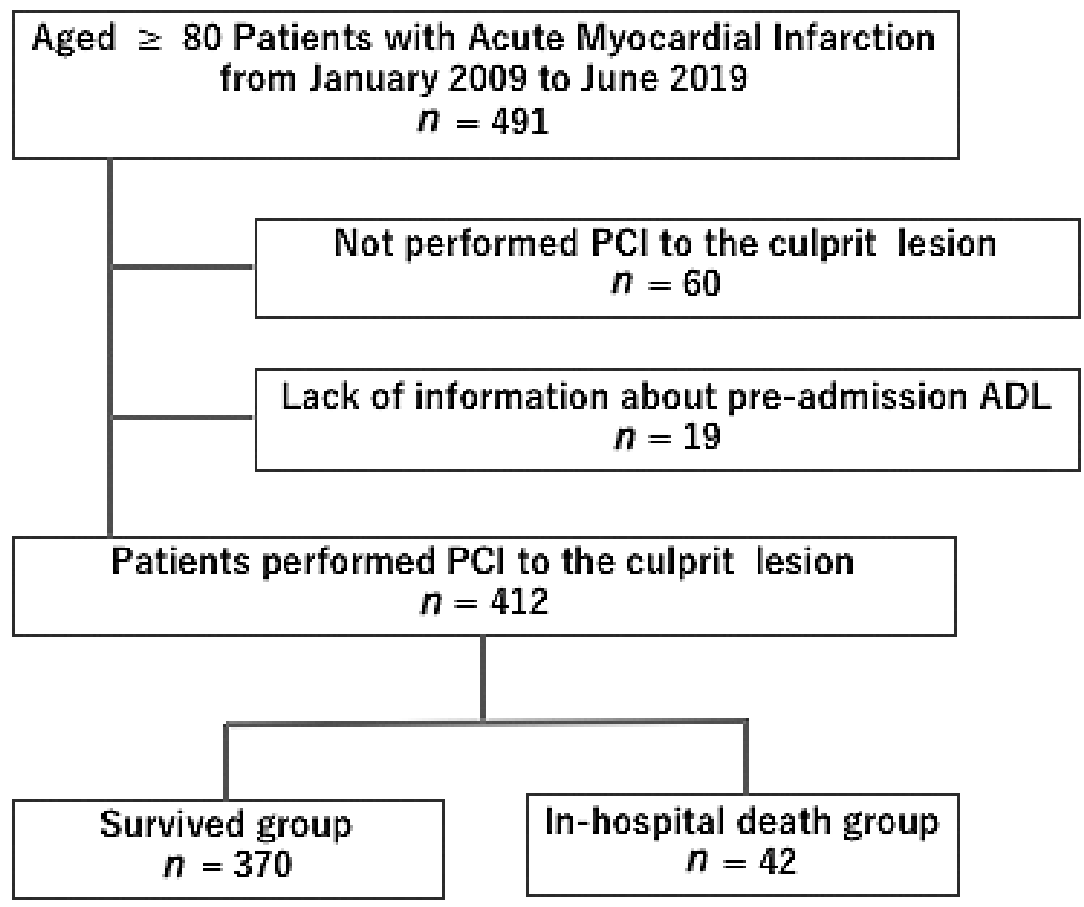

Figure. Study flowchart. PCI indicates percutaneous coronary intervention; and ADL, activities of daily living.

while other 41 patients died of cardiac death.

Table I shows the comparison of clinical characteristics between the two groups. Although most of their clinical characteristics were comparable, the frequency of anemia, Killip class, and the usage of mechanical circulatory support including IABP and VA-ECMO were significantly higher in the in-hospital death group than the survived group. Dependence in terms of having a meal, using the toilet, and changing clothes was more frequently observed in the in-hospital death group (having meal 14.3\%, using toilet $19.0 \%$, and changing clothes $23.8 \%$ ) than in the survived group (having meal $2.7 \%$, using toilet $8.6 \%$, and changing clothes $9.5 \%)(P=0.003$ for having meal, $P=$ 0.038 for using toilet, and $P=0.009$ for changing clothes). The mKATZ index was deemed to be significantly higher in the in-hospital death group than the survived group $(P=0.011)$. Table II shows the comparison of clinical outcomes between the two groups. As expected, peak creatinine kinase $(\mathrm{CPK})$ and creatinine kinase MB (CK-MB) levels were significantly higher in the inhospital death group $(\mathrm{CPK}, \mathrm{CK}-\mathrm{MB} 3556.1 \pm 4879.9 \mathrm{U} / \mathrm{L}$, $303.4 \pm 350.8 \mathrm{U} / \mathrm{L})$ than in the survived group (CPK, CKMB $1390.9 \pm 1863.9 \mathrm{U} / \mathrm{L}, 142.6 \pm 222.4 \mathrm{U} / \mathrm{L})(P<0.001$ for CPK, $P<0.001$ for CK-MB).

Univariate logistic regression analysis is presented in Table III. In-hospital death was significantly associated with Killip class III or IV, cardiac arrest, and use of mechanical circulatory support. The modified KATZ index was significantly associated with in-hospital death. Table IV shows the multivariate stepwise logistic regression analysis predicting in-hospital death. The following variables included were as follows: systolic blood pressure,
STEMI, onset to balloon time $<6$ hours, Killip class, cardiac arrest at prehospital or ER, hemoglobin levels, culprit left main trunk, trans-radial coronary intervention, drugeluting stent, use of temporary pacemaker, final TIMI flow grade 3, modified KATZ index, and mechanical circulatory support (IABP and/or VA-ECMO), which were all determined to have an association with in-hospital death in univariate analysis $(P<0.05)$. Cardiac arrest $(\mathrm{OR}$ 4.642, 95\% CI 1.177-18.305, $P=0.028$ ), Killip class III (versus Killip class I: OR 3.947, 95\% CI 1.233-12.639, $P$ $=0.021$ ), Killip class IV (versus Killip class I: OR 5.732, 95\% CI 1.976-16.630, $P=0.001$ ), modified KATZ index (OR 1.212, 95\% CI 1.001-1.469, $P=0.049$ ), hemoglobin levels (per $1 \mathrm{~g} / \mathrm{dL}$ increase :OR 0.803 , 95\% CI $0.656-$ $0.983,0.033$ ), use of temporary pacemaker (OR 2.603, 95\% CI 1.010-6.709, $P=0.048$ ), final TIMI flow grade 3 (versus TIMI $\leq 2$ :OR $0.240,95 \%$ CI $0.093-0.618, P=$ 0.003 ), and use of mechanical circulatory support (OR $4.264,95 \%$ CI $1.818-10.005, P=0.001$ ) were significantly associated with in-hospital death. Furthermore, the 6-point mKATZ index was significantly associated with inhospital death (OR 5.966, 95\% CI 1.522-23.387, $P=$ 0.010) (Table IV).

\section{Discussion}

We have included 412 AMI patients aged $\geq 80$ years old who reportedly underwent PCI for the culprit lesion in order to examine the determinants of in-hospital death. Although all study patients were treated using PCI, inhospital mortality $(10.2 \%)$ has remained high in this population. The multivariate logistic regression analysis 
Table I. Comparison of Patients' Characteristics Between the Survived and In-Hospital Death Groups

\begin{tabular}{|c|c|c|c|}
\hline & $\begin{array}{c}\text { Survived } \\
n=370\end{array}$ & $\begin{array}{c}\text { In-hospital death } \\
n=42\end{array}$ & $P$-value \\
\hline Age, years & $84.5 \pm 3.8(n=370)$ & $84.6 \pm 3.8(n=42)$ & 0.871 \\
\hline Nonagenarian, $n(\%)$ & $36(9.7)$ & $2(4.8)$ & 0.228 \\
\hline Female, $n(\%)$ & $150(40.5)$ & $15(35.7)$ & 0.545 \\
\hline \multicolumn{4}{|l|}{ Physical examination } \\
\hline Height $(\mathrm{cm})$ & $154.8 \pm 8.7(n=364)$ & $156.7 \pm 8.8(n=31)$ & 0.385 \\
\hline Body weight (kg) & $53.9 \pm 10.5(n=368)$ & $54.9 \pm 11.3(n=29)$ & 0.796 \\
\hline BMI & $22.4 \pm 3.4(n=364)$ & $22.2 \pm 3.5(n=29)$ & 0.633 \\
\hline Systolic blood pressure (mmHg) & $136.8 \pm 30.8(n=370)$ & $111.9 \pm 36.8(n=42)$ & $<0.001$ \\
\hline Diastolic blood pressure $(\mathrm{mmHg})$ & $75.0 \pm 19.2(n=370)$ & $64.6 \pm 20.6(n=42)$ & $<0.001$ \\
\hline Heart rate (beat per minute) & $81.3 \pm 23.4(n=370)$ & $82.7 \pm 28.8(n=42)$ & 0.579 \\
\hline \multicolumn{4}{|l|}{ Underlying disease } \\
\hline Hypertension, $n(\%)$ & $298(80.5)$ & $27(64.3)$ & 0.014 \\
\hline Diabetes mellitus, $n(\%)$ & $166(44.9)$ & $19(45.2)$ & 0.963 \\
\hline Dyslipidemia, $n(\%)$ & $167(45.1)$ & $19(45.2)$ & 0.990 \\
\hline Hemodialysis, $n(\%)$ & $18(4.9)$ & $3(7.1)$ & 0.363 \\
\hline History of previous PCI, $n(\%)$ & $75(20.3)$ & $8(19.0)$ & 0.832 \\
\hline History of previous CABG, $n(\%)$ & $14(3.8)$ & $2(4.8)$ & 0.504 \\
\hline STEMI, $n(\%)$ & $214(57.8)$ & $31(73.8)$ & 0.046 \\
\hline NSTEMI, $n(\%)$ & $156(42.2)$ & $11(26.2)$ & \\
\hline Anemia, $n(\%)$ & $202(54.6)$ & $35(83.3)$ & $<0.001$ \\
\hline Onset to balloon time, $n(\%)$ & & & 0.001 \\
\hline $0-6$ hours & $114(30.8)$ & $22(51.2)$ & \\
\hline 6-12 hours & $56(15.1)$ & $7(16.7)$ & \\
\hline 12-24 hours & $39(10.5)$ & $4(9.5)$ & \\
\hline Longer than 24 hours & $158(42.7)$ & $9(21.4)$ & \\
\hline Unknown/others & $3(0.8)$ & $0(0.0)$ & \\
\hline Killip class & & & $<0.001$ \\
\hline I & $231(62.4)$ & $7(16.7)$ & \\
\hline II & $51(13.8)$ & $5(11.9)$ & \\
\hline III & $45(1.4)$ & $7(16.7)$ & \\
\hline IV & $43(11.6)$ & $23(54.8)$ & \\
\hline Cardiac arrest at prehospital or ER, $n(\%)$ & $7(1.9)$ & $9(21.4)$ & $<0.001$ \\
\hline ST deviation, $n(\%)$ & $296(80.0)$ & $38(90.4)$ & 0.101 \\
\hline \multicolumn{4}{|l|}{ Medication before admission } \\
\hline Aspirin, $n(\%)$ & $121(32.7)$ & $11(26.2)$ & 0.658 \\
\hline Thienopyridine, $n(\%)$ & $59(15.9)$ & $6(14.3)$ & 0.993 \\
\hline Anticoagulant, $n(\%)$ & $19(5.1)$ & $1(2.4)$ & 0.429 \\
\hline Beta-blocker, $n(\%)$ & $80(21.6)$ & $6(14.3)$ & 0.406 \\
\hline ACE inhibitor, $n(\%)$ & $28(7.6)$ & $2(4.8)$ & 0.459 \\
\hline $\mathrm{ARB}, n(\%)$ & $143(38.6)$ & $9(21.4)$ & 0.070 \\
\hline Statin, $n(\%)$ & $124(33.5)$ & $11(26.2)$ & 0.579 \\
\hline Hypoglycemic agents, insulin, $n(\%)$ & $90(24.3)$ & $8(19.0)$ & 0.664 \\
\hline \multicolumn{4}{|l|}{ Laboratory data at admission } \\
\hline Serum albumin $(\mathrm{g} / \mathrm{dL})$ & $3.7 \pm 0.5(n=369)$ & $3.3 \pm 0.6(n=40)$ & $<0.001$ \\
\hline Serum creatinine $(\mathrm{mg} / \mathrm{dL})$ & $1.4 \pm 1.5(n=370)$ & $1.8 \pm 1.8(n=42)$ & $<0.001$ \\
\hline Hemoglobin $(\mathrm{g} / \mathrm{dL})$ & $12.2 \pm 1.8(n=370)$ & $11.1 \pm 1.9(n=42)$ & $<0.001$ \\
\hline HbA1c NGSP (\%) & $6.3 \pm 1.0(n=349)$ & $6.4 \pm 0.8(n=28)$ & 0.205 \\
\hline Culprit lesion & & & 0.044 \\
\hline Left main trunk, $n(\%)$ & $14(3.8)$ & $5(11.9)$ & \\
\hline LAD/Dx, $n(\%)$ & 169 (45.7) & $22(52.4)$ & \\
\hline $\mathrm{LCx} / \mathrm{HL}, n(\%)$ & $42(11.4)$ & $4(9.5)$ & \\
\hline Right coronary artery, $n(\%)$ & $124(33.5)$ & $8(19.0)$ & \\
\hline Graft/others, $n(\%)$ & $7(1.9)$ & $1(2.4)$ & \\
\hline Not determined, $n(\%)$ & $14(3.8)$ & $2(4.8)$ & \\
\hline Number of narrowed coronary arteries & & & 0.072 \\
\hline One-vessel disease, $n(\%)$ & $146(39.5)$ & $10(23.8)$ & \\
\hline Two-vessel disease, $n(\%)$ & $134(36.2)$ & $16(38.1)$ & \\
\hline Three-vessel disease, $n(\%)$ & $90(24.3)$ & $16(38.1)$ & \\
\hline \multicolumn{4}{|l|}{ Quantitative coronary angiography } \\
\hline Reference diameter $(\mathrm{mm})$ & $2.39 \pm 0.76(n=366)$ & $2.11 \pm 0.55(n=42)$ & 0.030 \\
\hline Lesion length (mm) & $15.7 \pm 9.2(n=366)$ & $18.7 \pm 11.0(n=42)$ & 0.102 \\
\hline
\end{tabular}


Table I. Comparison of Patients' Characteristics Between the Survived and In-Hospital Death Groups (continued)

\begin{tabular}{|c|c|c|c|}
\hline & $\begin{array}{c}\text { Survived } \\
n=370\end{array}$ & $\begin{array}{c}\text { In-hospital death } \\
n=42\end{array}$ & $P$-value \\
\hline Approach site & & & 0.070 \\
\hline Trans-radial coronary intervention, $n(\%)$ & $210(56.8)$ & $16(38.1)$ & \\
\hline Trans-femoral coronary intervention, $n(\%)$ & $148(40.0)$ & $24(57.1)$ & \\
\hline Trans-brachial coronary intervention, $n(\%)$ & $12(3.2)$ & $2(4.8)$ & \\
\hline PCI procedure & & & 0.011 \\
\hline Drug-eluting stent, $n(\%)$ & $289(78.1)$ & $26(61.9)$ & \\
\hline Bare metal stent, $n(\%)$ & $51(13.8)$ & $6(14.3)$ & \\
\hline Plain old balloon angioplasty, $n(\%)$ & $23(6.2)$ & $9(21.4)$ & \\
\hline DES and BMS, $n(\%)$ & $1(0.3)$ & $0(0.0)$ & \\
\hline Other failure, $n(\%)$ & $6(1.6)$ & $1(2.4)$ & \\
\hline Stent diameter $(\mathrm{mm})$ & $2.8 \pm 0.4(n=341)$ & $2.8 \pm 0.4(n=31)$ & 0.332 \\
\hline Stent length $(\mathrm{mm})$ & $27.5 \pm 15.2(n=341)$ & $30.4 \pm 14.6(n=31)$ & 0.118 \\
\hline Aspiration, $n(\%)$ & $84(22.7)$ & $10(23.8)$ & 0.871 \\
\hline Temporary pacemaker, $n(\%)$ & $39(10.5)$ & $9(21.4)$ & 0.041 \\
\hline Rotablator, $n(\%)$ & $21(5.7)$ & $2(4.8)$ & 0.578 \\
\hline Intra-aortic balloon pumping support, $n(\%)$ & $39(10.5)$ & $12(28.6)$ & 0.001 \\
\hline Percutaneous cardiopulmonary support, $n(\%)$ & $5(1.4)$ & $11(26.2)$ & $<0.001$ \\
\hline IABP and/or VA-ECMO, $n(\%)$ & $41(11.1)$ & $20(47.6)$ & $<0.001$ \\
\hline Initial TIMI flow grade & & & 0.065 \\
\hline 0 & $111(30.0)$ & $19(45.2)$ & \\
\hline 1 & $35(9.5)$ & $5(11.9)$ & \\
\hline 2 & $68(18.4)$ & $9(21.4)$ & \\
\hline 3 & $156(42.2)$ & $9(21.4)$ & \\
\hline Final TIMI flow grade & & & 0.036 \\
\hline 0 & $7(1.9)$ & $0(0.0)$ & \\
\hline 1 & $8(2.2)$ & $4(9.5)$ & \\
\hline 2 & $17(4.6)$ & $6(14.3)$ & \\
\hline 3 & $338(91.4)$ & $32(76.2)$ & \\
\hline Dependence of having meals & $10(2.7)$ & $6(14.3)$ & 0.003 \\
\hline Dependence of using the toilet & $32(8.6)$ & $8(19.0)$ & 0.038 \\
\hline Dependence of maintaining cleanliness & $51(13.8)$ & $10(23.8)$ & 0.083 \\
\hline Dependence of washing face & $31(8.4)$ & $7(16.7)$ & 0.077 \\
\hline Dependence of changing clothes & $35(9.5)$ & $10(23.8)$ & 0.009 \\
\hline Dependence of moving around & $51(13.8)$ & $10(23.8)$ & 0.083 \\
\hline Modified KATZ index & & & 0.011 \\
\hline 0 & $305(82.4)$ & $30(71.4)$ & \\
\hline 1 & $18(4.9)$ & $3(7.1)$ & \\
\hline 2 & $9(2.4)$ & $0(0.0)$ & \\
\hline 3 & $8(2.2)$ & $1(2.4)$ & \\
\hline 4 & $8(2.2)$ & $1(2.4)$ & \\
\hline 5 & $14(3.8)$ & $1(2.4)$ & \\
\hline 6 & $8(2.2)$ & $6(14.3)$ & \\
\hline
\end{tabular}

Data are expressed as the mean \pm SD or number (percentage). A Student's $t$-test was used for normally distributed continuous variables, while Mann-Whitney $U$ test was used for abnormally distributed continuous variables, and a chi-square test was used for categorical variables. BMI indicates body mass index; PCI, percutaneous coronary intervention; CABG, coronary artery bypass grafting; STEMI, ST-elevation myocardial infarction; NSTEMI, non-ST-elevation myocardial infarction; ER, emergency room; ACE, angiotensin-converting enzyme; ARB, angiotensin II receptor blocker; HbAlc NGSP, hemoglobin A1c National Glycohemoglobin Standardization Program; LAD, left anterior descending artery; Dx, diagonal branch; LCx, left circumflex; HL, high lateral branch; IABP, intra-aortic balloon pumping support; VA-ECMO, veno-arterial extracorporeal membrane oxygenation; and TIMI, thrombolysis in myocardial infarction. 
Table II. Comparison of Clinical Outcomes Between the Survived and In-Hospital Death Groups

\begin{tabular}{lrrr}
\hline & \multicolumn{1}{c}{ Survived } & \multicolumn{1}{c}{ In-hospital death } & \multicolumn{1}{c}{$P$-value } \\
& \multicolumn{1}{c}{$n=339$} & \multicolumn{1}{c}{$n=37$} & \\
\hline Length of hospital stay (days) & $13.8 \pm 7.8(n=370)$ & $11.6 \pm 3.5(n=42)$ & 0.002 \\
Length of CCU stay (days) & $4.0 \pm 0.9(n=370)$ & $7.1 \pm 1.6(n=42)$ & 0.346 \\
Peak creatinine kinase (U/L) & $1390.9 \pm 1863.9(n=370)$ & $3556.1 \pm 4879.9(n=42)$ & $<0.001$ \\
Peak creatinine kinase MB (U/L) & $142.6 \pm 222.4(n=369)$ & $303.4 \pm 350.8(n=42)$ & $<0.001$ \\
Left ventricular ejection fraction (\%) & $51.6 \pm 3.2(n=351)$ & $33.6 \pm 2.8(n=34)$ & $<0.001$ \\
\hline
\end{tabular}

Data are expressed as the mean \pm SD. Mann-Whitney $U$ test was used for abnormally distributed continuous variables. CCU indicates coronary care unit.

identified the independent risk factors of in-hospital death such as cardiac arrest at prehospital or ER, Killip class III and IV, mKATZ index, hemoglobin level at admission, use of temporary pacemaker, final TIMI flow grade, and use of mechanical circulatory support. With our study population being limited to the very elderly who underwent PCI, established risk factors (cardiac arrest, high Killip class, final TIMI flow grade, and use of mechanical circulatory support) have remained significant determinants of in-hospital death. Of note, pre-admission ADL evaluated using mKATZ index was found to be significantly associated with in-hospital death, which suggests the usefulness of mKATZ index in identifying very elderly with AMI who are at high risk.

Previous studies have reported on the risk factors associated with poor clinical outcomes among patients with AMI. ${ }^{16-18)}$ Meanwhile, our findings showed that the use of mechanical circulatory support and temporary pacemaker was significantly associated with in-hospital death. As most patients requiring mechanical circulatory support and/or temporary pacemaker have severe condition such as cardiogenic shock and/or bradycardia, use of those devices would reflect the severity of illness rather than the cause of death. It is not surprising if the patients who required mechanical circulatory support had poor clinical outcomes, as refractory cardiogenic shock and cardiac arrest were associated with the highest mortality. ${ }^{15,19,20)}$ Moreover, the prevalence of Killip class III-IV was determined to be at $28.6 \%$ in this present study. Since Uemura, et al. reported the prevalence of Killip class III-IV was at $18.4 \%$ in AMI patients aged $<75$ years old, ${ }^{5}$ the relatively higher prevalence of Killip class III-IV in the very elderly might affect the significant association between the use of mechanical support and in-hospital death. On the other hand, the onset to balloon time was significantly longer in the survived group than that in the in-hospital death group in this present study, contrary to other studies. $^{21)}$ The very elderly might not recognize the symptom of AMI, when the severity of AMI was either mild or moderate. Hemoglobin levels at admission also were also determined to be associated with in-hospital death, based on our findings. Previous studies reported that hemoglobin level declines with advancing age and anemia is also common in patients with cardiovascular diseases. ${ }^{22)}$ Furthermore, hemoglobin levels were reported as an independent predictor of in-hospital and long-term mortality among the patients with AMI. ${ }^{23,24)}$ Low hemoglobin levels have been identified to have the potential to aggravate myocardial ischemia by decreasing the oxygen content of blood sup- ply to the myocardium. ${ }^{23)}$ Anemia also increases myocardial oxygen demand through necessitating a higher stroke volume and heart rate to maintain adequate systemic oxygen delivery. ${ }^{25}$ ) Furthermore, the strong association between anemia and frailty including sarcopenia was also reported, ${ }^{26}$ ) which might affect the clinical outcomes in AMI patients with anemia. In our study, final TIMI flow grade $\leq 2$ was correlated with in-hospital death. Previous studies reported that good final TIMI flow grade after PCI was associated with favorable clinical outcomes. ${ }^{27,28)}$ Our study confirms that final TIMI 3 flow is an important factor for favorable outcomes even in the very elderly patients.

We should discuss the strong association between the pre-admission ADL and in-hospital death. First, ADL in the elderly is closely related with frailty. In fact, the KATZ index has been used as an index of frailty in early studies. ${ }^{29,30)}$ Because the patients' health status does not always depend on their chronological age, ${ }^{31)}$ frailty has now been considered as an emerging concept in clinical practice, highly prevalent among the very elderly. ${ }^{32,33)}$ Furthermore, frailty was significantly associated with the morbidity and mortality of other cardiovascular diseases such as heart failure or post-transcatheter aortic valve implantation. ${ }^{30,34,35)}$ Therefore, since the mKATZ index represented frailty in our study population, there might be an association between mKATZ index and in-hospital death. Moreover, we might hesitate to perform invasive treatments such as mechanical circulatory support or use of ventilator for the very elderly with poor ADL, although we underwent primary PCI as long as the patient was cooperative with us during PCI. As compared to the five-point mKATZ index, the six-point mKATZ was determined to be significantly associated with in-hospital death. Because the six-point mKATZ represents the poorest ADL, patients or patient's families might refuse invasive treatments such as ventilation. As a result, the very elderly with poor ADL might not receive invasive treatments except primary PCI, resulting in in-hospital death.

As compared to previous studies, the following similarities to our present study were identified: (1) cardiogenic shock and anemia were significantly associated with in-hospital death in patients with AMI, and (2) poor preadmission ADL was significantly associated with inhospital death. On the other hand, the new findings of this present study were as follows: (1) we might confirm that the risk factors were similar between the general population and the very elderly aged $\geq 80$ years old, and (2) we have found the usefulness of modified KATZ index, 
Table III. Univariate Logistic Regression Analysis Predicting In-Hospital Death

\begin{tabular}{|c|c|c|c|}
\hline Variables & Odds ratios & $95 \%$ confidence interval & $P$-value \\
\hline Age (per 10 years) $(n=412)$ & 0.880 & $0.445-1.743$ & 0.715 \\
\hline Female $(n=412)$ & 0.815 & $0.419-1.583$ & 0.546 \\
\hline BMI $(n=393)$ & 0.978 & 0.874-1.094 & 0.696 \\
\hline Systolic blood pressure (per $10 \mathrm{mmHg})(n=412)$ & 0.758 & $0.674-0.851$ & $<0.001$ \\
\hline Diastolic blood pressure (per $10 \mathrm{mmHg})(n=412)$ & 0.732 & $0.608-0.882$ & 0.001 \\
\hline Heart rate (per 10), beats per minute $(n=412)$ & 0.802 & $0.890-1.162$ & 0.802 \\
\hline Hypertension $(n=412)$ & 0.435 & $0.220-0.860$ & 0.017 \\
\hline Diabetes mellitus $(n=412)$ & 1.015 & $0.535-1.928$ & 0.963 \\
\hline Dyslipidemia $(n=412)$ & 1.004 & $0.529-1.907$ & 0.990 \\
\hline Hemodialysis $(n=412)$ & 1.504 & $0.424-5.336$ & 0.527 \\
\hline History of previous PCI $(n=409)$ & 0.916 & $0.407-2.061$ & 0.832 \\
\hline History of previous CABG $(n=409)$ & 1.261 & $0.276-5.748$ & 0.765 \\
\hline STEMI $(n=412)$ & 2.054 & $1.002-4.213$ & 0.049 \\
\hline Anemia $(n=412)$ & 4.158 & $1.801-9.603$ & 0.001 \\
\hline ST deviation $(n=412)$ & 2.375 & $0.822-6.864$ & 0.110 \\
\hline Onset to balloon time $<6$ hours $(n=412)$ & 2.470 & $1.297-4.706$ & 0.006 \\
\hline \multicolumn{4}{|l|}{ Killip class $(n=412)$} \\
\hline II (versus I) & 3.235 & $0.987-10.603$ & 0.053 \\
\hline III (versus I) & 5.133 & $1.717-15.348$ & 0.003 \\
\hline IV (versus I) & 17.651 & 7.130-43.699 & $<0.001$ \\
\hline Killip class III or IV $(n=412)$ & 8.011 & $3.935-16.310$ & $<0.001$ \\
\hline Cardiac arrest at prehospital or ER $(n=412)$ & 14.143 & $4.949-40.417$ & $<0.001$ \\
\hline \multicolumn{4}{|l|}{ Laboratory data at admission } \\
\hline Serum albumin, g/dL $(n=409)$ & 0.235 & $0.129-0.429$ & $<0.001$ \\
\hline Serum creatinine, $\mathrm{mg} / \mathrm{dL}(n=412)$ & 1.164 & $0.988-1.373$ & 0.070 \\
\hline Hemoglobin, g/dL $(n=412)$ & 0.734 & $0.620-0.869$ & $<0.001$ \\
\hline HbAlc NGSP, $\%(n=377)$ & 1.068 & $0.750-1.521$ & 0.714 \\
\hline LVEF, $\%(n=385)$ & 0.905 & $0.876-0.934$ & $<0.001$ \\
\hline Culprit lesion left main trunk $(n=412)$ & 3.436 & $1.172-10.076$ & 0.025 \\
\hline Culprit lesion LAD/Dx $(n=412)$ & 1.308 & $0.690-2.479$ & 0.410 \\
\hline Three-vessel disease $(n=412)$ & 1.915 & $0.983-3.728$ & 0.056 \\
\hline \multicolumn{4}{|l|}{ Quantitative coronary angiography } \\
\hline Reference diameter, $\mathrm{mm}(n=408)$ & 0.538 & $0.320-0.904$ & 0.019 \\
\hline Lesion length, $\mathrm{mm}(n=408)$ & 1.029 & $1.000-1.058$ & 0.053 \\
\hline Trans-radial coronary intervention $(n=412)$ & 0.469 & $0.243-0.903$ & 0.024 \\
\hline Drug-eluting stent $(n=412)$ & 0.412 & $0.212-0.800$ & 0.009 \\
\hline Bare metal stent $(n=412)$ & 1.042 & $0.418-2.599$ & 0.929 \\
\hline Aspiration $(n=412)$ & 1.064 & $0.502-2.254$ & 0.871 \\
\hline Temporary pacemaker $(n=412)$ & 2.315 & $1.031-5.194$ & 0.042 \\
\hline Stent diameter $(n=372)$ & 0.691 & $0.304-1.572$ & 0.379 \\
\hline Stent length $(n=372)$ & 1.011 & $0.990-1.032$ & 0.304 \\
\hline Final TIMI flow grade $\leq 2(n=412)$ & 3.301 & $1.487-7.326$ & 0.003 \\
\hline Final TIMI flow grade $3(n=412)$ & 0.303 & $0.137-0.672$ & 0.003 \\
\hline $\operatorname{IABP}(n=412)$ & 3.395 & $1.608-7.167$ & 0.001 \\
\hline VA-ECMO $(n=412)$ & 25.903 & $8.461-79.303$ & $<0.001$ \\
\hline Mechanical circulatory support (IABP and/or VA-ECMO) $(n=412)$ & 7.295 & $3.670-14.501$ & $<0.001$ \\
\hline Modified KATZ index $(n=412)$ & 1.225 & $1.043-1.439$ & 0.014 \\
\hline Modified KATZ index 6 points (versus I) $(n=412)$ & 7.542 & $2.479-22.942$ & $<0.001$ \\
\hline
\end{tabular}

BMI indicates body mass index; PCI, percutaneous coronary intervention; CABG, coronary artery bypass grafting; STEMI, ST-elevation myocardial infarction; ER, emergency room; GRACE, the Global Registry of Acute Coronary Events; HbA1c NGSP, Hemoglobin A1c National Glycohemoglobin Standardization Program; LVEF, left ventricular ejection fraction; LAD, left anterior descending artery; Dx, diagonal branch; TIMI, thrombolysis in myocardial infarction; IABP, intra-aortic balloon pumping support; and VA-ECMO, veno-arterial extracorporeal membrane oxygenation.

which is easier to calculate than other frailty $\operatorname{scores}^{34,36)}$ in AMI patients aged $\geq 80$ years old.

Clinical implications of this present study should be noted. First, we may evaluate the pre-admission ADL such as KATZ index or mKATZ index in finding the highestrisk group among the very elderly with AMI. The mKATZ index may be useful in making decisions, for ex- ample, whether the very elderly patients can tolerate intensive care including mechanical circulatory support. Moreover, because the mKATZ index can be evaluated from a simple interview with patients or with their family, it would take only a few minutes to complete the mKATZ index. Second, cardiac arrest, high Killip class, low hemoglobin levels, and use of mechanical circulatory support 
Table IV. Multivariable Stepwise Logistic Regression Analysis Predicting In-Hospital Death

\begin{tabular}{|c|c|c|c|}
\hline Independent variables & Odds ratios & $95 \%$ confidence interval & $P$-value \\
\hline \multicolumn{4}{|l|}{ Model 1} \\
\hline Cardiac arrest at prehospital or ER & 4.642 & $1.177-18.305$ & 0.028 \\
\hline \multicolumn{4}{|l|}{ Killip class } \\
\hline II (versus Killip class I) & 3.426 & $0.966-11.776$ & 0.051 \\
\hline III (versus Killip class I) & 3.947 & $1.233-12.639$ & 0.021 \\
\hline IV (versus Killip class I) & 5.732 & $1.976-16.630$ & 0.001 \\
\hline Modified KATZ index & 1.212 & $1.001-1.469$ & 0.049 \\
\hline Hemoglobin (per $1 \mathrm{~g} / \mathrm{dL}$ increase) & 0.803 & $0.656-0.983$ & 0.033 \\
\hline Temporary pacemaker & 2.603 & $1.010-6.709$ & 0.048 \\
\hline Final TIMI flow grade 3 (versus TIMI $\leq 2$ ) & 0.240 & $0.093-0.618$ & 0.003 \\
\hline Mechanical circulatory support & 4.264 & $1.818-10.005$ & 0.001 \\
\hline \multicolumn{4}{|l|}{ Model 2} \\
\hline Cardiac arrest at prehospital or ER & 4.386 & $1.107-17.318$ & 0.035 \\
\hline \multicolumn{4}{|l|}{ Killip class } \\
\hline II (versus Killip class I) & 3.506 & $1.005-12.239$ & 0.049 \\
\hline III (versus Killip class I) & 4.057 & $1.259-13.072$ & 0.019 \\
\hline IV (versus Killip class I) & 5.839 & $1.989-17.143$ & 0.001 \\
\hline Modified KATZ index 6 points (versus mKATZ index 1-5) & 5.966 & $1.522-23.387$ & 0.010 \\
\hline Hemoglobin (per $1 \mathrm{~g} / \mathrm{dL}$ increase) & 0.824 & $0.671-1.012$ & 0.065 \\
\hline Temporary pacemaker & 2.835 & $1.085-7.4121$ & 0.034 \\
\hline Final TIMI flow grade 3 (versus TIMI $\leq 2$ ) & 0.254 & $0.097-0.666$ & 0.005 \\
\hline Mechanical circulatory support & 4.173 & $1.783-9.768$ & 0.001 \\
\hline
\end{tabular}

The table shows multivariate stepwise logistic regression analysis predicting in-hospital mortality. The variables described below were entered: systolic blood pressure, STEMI, Hemoglobin, onset-to-balloon time $<6$ hours, Killip class, cardiac arrest at prehospital or ER, culprit left main trunk, trans-radial coronary intervention, Drug eluting stent, Final TIMI flow grade 3, modified KATZ index, use of temporary pacemaker, and mechanical circulatory support.

and temporary pacemaker have remained to be the highrisk indicators in the very elderly with AMI. We should consider a more aggressive management for the very elderly with cardiogenic shock and/or anemia to save their lives.

Study Limitations: This study has been determined with several limitations. Since this study was a single-center, retrospective observational study, there is a risk of selection bias. Because the mortality of the excluded patients was found greater than that of the study patients, we might have missed potential risk factors for in-hospital death. Although we included consecutive AMI patients in our hospital, a non-PCI-capable hospital might not ask us to transfer patients who were not cooperative with primary PCI. Since the study period was long (from January 2009 to June 2019), our strategy for AMI such as indication of primary PCI or rehabilitation program was deemed not consistent for the study period, especially after April $2015 .^{37,38)}$ Furthermore, the work-up for the causes of anemia was insufficient in most study patients; this could be attributed to the comorbidities including cognitive dysfunction, frailty, and chronic kidney disease. Therefore, we could not precisely determine the main reason of anemia in most study participants. Lastly, we also failed in evaluating original KATZ index due to lacking information regarding bathing.

\section{Conclusions}

Our findings showed that in-hospital outcomes of AMI in the very elderly have remained poor in the current
PCI era. The multivariate analysis has identified poor preadmission ADL as well as cardiogenic shock and anemia to be associated with in-hospital death. Thus, a simple evaluation of pre-admission ADL would be very useful in stratifying the very elderly with AMI for better clinical outcomes.

\section{Acknowledgments}

We are grateful for the support of the entire staff of the catheterization laboratory, CCU, and cardiology ward of Saitama Medical Center, Jichi Medical University.

\section{Disclosure}

Conflicts of interest: Dr. Sakakura has received speaking honoraria from Abbott Vascular, Boston Scientific, Medtronic Cardiovascular, Terumo, OrbusNeich, Japan Lifeline, and NIPRO. He has served as a proctor for Rotablator for Boston Scientific and has served as a consultant for Abbott Vascular and Boston Scientific. Prof. Fujita served as a consultant for Mehergen Group Holdings, Inc.

\section{References}

1. Elderly population estimates. Available at: https://www.stat.go.jp/ data/topics/topi901.html. Accessed May 12, 2020.

2. Cui Y, Wang Q, Liu S, Sun R, Zhou Y, Li Y. Age-related variations in intestinal microflora of free-range and caged hens. Front Microbiol 2017; 8: 1310. 
3. TIME Investigators. Trial of invasive versus medical therapy in elderly patients with chronic symptomatic coronary-artery disease (Time): a randomised trial. Lancet 2001; 358: 951-7.

4. Seguchi M, Sakakura K, Yamamoto K, et al. Comparison of inhospital clinical outcomes of acute myocardial infarction between nonagenarians and octogenarians. Int Heart J 2020; 61: 7-14.

5. Uemura S, Okamoto H, Nakai M, et al. Primary percutaneous coronary intervention in elderly patients with acute myocardial infarction- an analysis from a Japanese nationwide claim-based database. Circ J 2019; 83: 1229-38.

6. García-Blas S, Bonanad C, Sanchis J. Invasive strategy in elderly patients with acute coronary syndrome in 2018: close to the truth? J Geriatr Cardiol 2019; 16: 114-20.

7. Watanabe Y, Sakakura K, Taniguchi Y, et al. Determinants of inhospital death in acute myocardial infarction with triple vessel disease. Int Heart J 2016; 57: 697-704.

8. Tsukui T, Sakakura K, Taniguchi Y, et al. Determinants of short and long door-to-balloon time in current primary percutaneous coronary interventions. Heart Vessels 2018; 33: 498-506.

9. Kasahara T, Sakakura K, Yamamoto K, et al. Clinical factors associated with in-hospital mortality in patients with acute myocardial infarction who required intra-aortic balloon pumping. Int Heart J 2020; 61: 209-14.

10. Yamamoto K, Sakakura K, Akashi N, et al. Clinical outcomes of left main crossover stenting for ostial left anterior descending artery acute myocardial infarction. Heart Vessels 2018; 33: 3340.

11. Lee WC, Fang HY, Chen HC, et al. Anemia: A significant cardiovascular mortality risk after ST-segment elevation myocardial infarction complicated by the comorbidities of hypertension and kidney disease. PLOS ONE 2017; 12: e0180165.

12. Sakakura K, Taniguchi Y, Yamamoto K, Wada H, Momomura SI, Fujita H. Halfway rotational atherectomy for calcified lesions: comparison with conventional rotational atherectomy in a propensity-score matched analysis. PLOS ONE 2019; 14: e0219289.

13. Helal AM, Shaheen SM, Elhammady WA, Ahmed MI, AbdelHakim AS, Allam LE. Primary PCI versus pharmacoinvasive strategy for ST elevation myocardial infarction. Int J Cardiol Heart Vasc 2018; 21: 87-93.

14. Katz S, Ford AB, Moskowitz RW, Jackson BA, Jaffe MW. Studies of illness in the aged. The Index ADL Standardized Meas Biol Psychosoc Funct JAMA 1963; 185: 914-9.

15. Taniguchi Y, Sakakura K, Adachi Y, et al. In-hospital outcomes of acute myocardial infarction with cardiogenic shock caused by right coronary artery occlusion vs. left coronary artery occlusion. Cardiovasc Interv Ther 2018; 33: 338-44.

16. Bates ER, Tamis-Holland JE, Bittl JA, O'Gara PT, Levine GN. PCI strategies in patients with ST-segment elevation myocardial infarction and multivessel coronary artery disease. J Am Coll Cardiol 2016; 68: 1066-81.

17. Vicent L, Velásquez-Rodríguez J, Valero-Masa MJ, et al. Predictors of high Killip class after ST segment elevation myocardial infarction in the era of primary reperfusion. Int J Cardiol 2017; 248: 46-50.

18. Thiele H, Akin I, Sandri M, et al. PCI strategies in patients with acute myocardial infarction and cardiogenic shock. N Engl J Med 2017; 377: 2419-32.

19. Negi SI, Sokolovic M, Koifman E, et al. Contemporary use of veno-arterial extracorporeal membrane oxygenation for refractory cardiogenic shock in acute coronary syndrome. J Invas Cardiol 2016; 28: 52-7.

20. Sakamoto S, Taniguchi N, Nakajima S, Takahashi A. Extracorporeal life support for cardiogenic shock or cardiac arrest due to acute coronary syndrome. Ann Thorac Surg 2012; 94: 1-7.

21. Shiomi H, Nakagawa Y, Morimoto T, et al. Association of onset to balloon and door to balloon time with long term clinical outcome in patients with ST elevation acute myocardial infarction having primary percutaneous coronary intervention: observational study. BMJ 2012; 344: e3257.

22. Archbold RA, Balami D, Al-Hajiri A, et al. Hemoglobin concentration is an independent determinant of heart failure in acute coronary syndromes: cohort analysis of 2310 patients. Am Heart J 2006; 152: 1091-5.

23. Velásquez-Rodríguez J, Diez-Delhoyo F, Valero-Masa MJ, et al. Prognostic impact of age and hemoglobin in acute ST-segment elevation myocardial infarction treated with reperfusion therapy. Am J Cardiol 2017; 119: 1909-16.

24. McKechnie RS, Smith D, Montoye C, et al. Prognostic implication of anemia on in-hospital outcomes after percutaneous coronary intervention. Circulation 2004; 110: 271-7.

25. Sabatine MS, Morrow DA, Giugliano RP, et al. Association of hemoglobin levels with clinical outcomes in acute coronary syndromes. Circulation 2005; 111: 2042-9.

26. Artz AS. Anemia and the frail elderly. Semin Hematol 2008; 45 : 261-6.

27. Kim DW, Her SH, Park MW, et al. Impact of postprocedural TIMI flow on long-term clinical outcomes in patients with acute myocardial infarction. Int Heart J 2017; 58: 674-85.

28. Ndrepepa G, Mehilli J, Schulz S, et al. Prognostic significance of epicardial blood flow before and after percutaneous coronary intervention in patients with acute coronary syndromes. J Am Coll Cardiol 2008; 52: 512-7.

29. Puls M, Sobisiak B, Bleckmann A, et al. Impact of frailty on short- and long-term morbidity and mortality after transcatheter aortic valve implantation: risk assessment by Katz Index of activities of daily living. EuroIntervention 2014; 10: 609-19.

30. Kleczynski P, Dziewierz A, Bagienski M, et al. Impact of frailty on mortality after transcatheter aortic valve implantation. Am Heart J 2017; 185: 52-8.

31. Lee DH, Buth KJ, Martin BJ, Yip AM, Hirsch GM. Frail patients are at increased risk for mortality and prolonged institutional care after cardiac surgery. Circulation 2010; 121: 973-8.

32. Carneiro JA, Cardoso RR, Durães MS, et al. Frailty in the elderly: prevalence and associated factors. Rev Bras Enferm 2017; 70: 747-52.

33. Verlaan S, Ligthart-Melis GC, Wijers SLJ, Cederholm T, Maier $\mathrm{AB}$, de van der Schueren MAE. High prevalence of physical frailty among community-dwelling malnourished older adults-A systematic review and meta-analysis. J Am Med Dir Assoc 2017; 18: 374-82.

34. Fried LP, Tangen CM, Walston J, et al. Frailty in older adults: evidence for a phenotype. J Gerontol A Biol Sci Med Sci 2001; 56: M146-56.

35. McDonagh J, Ferguson C, Newton PJ. Frailty assessment in heart failure: an overview of the multi-domain approach. Curr Heart Fail Rep 2018; 15: 17-23.

36. Kodama A, Koyama A, Sugimoto M, Niimi K, Banno H, Komori K. Association between preoperative frailty and mortality in patients with critical limb ischemia following infrainguinal bypass surgery-usefulness of the Barthel index. Circ J 2017; 82: 267-74.

37. Yamamoto K, Sakakura K, Akashi N, et al. Novel acute myocardial infarction risk stratification (nARS) system reduces the length of hospitalization for acute myocardial infarction. Circ J 2019; 83: 1039-46.

38. Yamamoto K, Sakakura K, Akashi N, et al. Clinical outcomes after acute myocardial infarction according to a novel stratification system linked to a rehabilitation program. J Cardiol 2018; 72: 227-33. 